\title{
Jamaica-The Transformation Towards Sustainability of an Island Economy Under Austerity Measures
}

This chapter diverges from the previous case studies. In addition to a literature review and qualitative interviews of local stakeholders, this chapter also contextualizes sustainable, low-carbon transformation by using an innovative experiment, where participants played the role of a decision-making government official committing to decisions under specific conditions (e.g., imposed austerity measures). When applied to Jamaica, the specific parameters of a scenario are assumed and through solution-oriented role playing, the process of decision-making is analyzed. The experiment employs a method, where a decision-making process is given a concrete space and time, which allows the identification of the main drivers and dynamics. These dynamics may be significant when tracing the course of the process.

The aim of this chapter is, as with the previous case studies, to provide an empirical basis for new or revisited theoretical concepts. As in the previous case studies, this chapter commences with the contextualization of the transformation process in Jamaica through literature review and interviews. What are the unique factors that drive the behavior of various actors? What challenges and caveats inhibit the kind of policy-making that embraces sustainable, low-carbon transformation? Which entry points to climate mitigation can be useful in disentangling Jamaica from its multi-layered and complex carbon lock-ins?

The simulation game was designed and conducted by the author within the framework of a collaboration project between the University of Technology (UTECH) in Kingston, the CARICOM, and the Deutsche Gesellschaft für internationale Zusammenarbeit (GIZ), where the author developed seven modules of the newly established master's Degree in Sustainable Energy and Climate Change, Innovation and Entrepreneurship. Participants of the simulation game were professionals from both the private and public sector, and who were enrolled 
in the module on energy and environmental policies \& economies. The professional background of the participants implies that they have significant (practical) knowledge of the issues involved. Most of the students are direct stakeholders in the low-carbon transformation process, which explains their enrolment in the master's program and allowing the simulation game to touch upon institutional memories and professional culture.

\subsection{Context-Stumbling Blocks and Barriers to Sustainable, Low-Carbon Transformation}

As the theoretical model (ideal type) demonstrates, the contextualization of Jamaica's transformation process will highlight the exogenous and endogenous factors that drive or hinder various processes relevant to the country's sustainable, low-carbon transformation.

\subsubsection{Carbon Lock-Ins}

Sustainable, low-carbon transformation is an elusive project in Jamaica (see Makhijani et al. 2013; UNFCCC 2015; GRICCE 2017). Political, social, technological, geophysical, and economic conditions are inauspicious to sustainable, low-carbon system transformation. Suitable policies to achieve sustainable and low-carbon growth are effectively inhibited by (carbon) lock-ins (Charvis \& Heron 2016). For example, the decision to construct the Freedom Highway from Kingston to the Northern part of the Islands inhibits the development of the railway system, as provisions were made to avoid direct competition with the toll-collecting highway (Williams 2016). The country's high dependence on fossil fuels in terms of GDP/energy ratio and in almost all of its human activities is paradigmatic. Carbon lock-ins in Jamaica have limited the effectiveness of energy policies as stipulated by the National Energy Policy (2009-2030), the Addendum on Energy Conservation and Efficiency (2008-2022), the updated version of the National Energy Conservation and Efficiency Policy 2010-2030, and the Vision 2030 Jamaica (National Development Plan). These policies aim to promote energy conservation and efficiency. Such carbon lock-ins are complemented by an inability in effectively addressing the shortcomings of renewable energies, such as the intermittency of wind energy (Reynolds 2016; Willie \& Morgan 2016) 
Often labelled as a 'hostage' to oil, Jamaica's oil imports exceeded the value of its total exported goods by 118 percent in 2010 (Ahmed 2017). Imported oil provides approximately 95 percent of the country's primary energy services and accounts for over 90 percent of electricity production (MSET 2017), making Jamaica highly vulnerable to oil price volatility. Serious implications for the balance of payments, inflation, business competitiveness, and household poverty can be connected to Jamaica's energy insecurity. Exacerbating Jamaica's energy insecurity further, is its high energy intensity and high inefficiency in the use of energy resources. Due to the central role of the bauxite and alumina industries, Jamaica consumes an average of 4,800 kWh per US\$1,000 of GDP, which is very high compared to other Latin American and Caribbean countries (MSET 2017). Electricity losses on the grid are high, at 22.3 percent, of which 10 percent are technical and the rest are from theft and illegal connections (MSET 2017). In addition, as Al Binger (2011) highlights, Jamaica wastes more than half of the available energy from imported fuels.

The transport sector of Jamaica is the largest consumer of petroleum, accounting for 42 percent of total petroleum consumption in 2008 (Binger 2011). Still, with the relatively expensive toll fees of the highway to sustain its operations, the Jamaican government cannot reopen its passenger train service, which may undermine the operations of the national highway. As the officials of the Jamaican Railway Corporation highlighted during an interview (Hernandez 2016), railway services are unable to compete with other modes of transport, because of high maintenance costs and the lack of investment in infrastructure. In addition, ambitious and eventually radical efforts are needed to allow the shift to a carbon-neutral transportation sector. However, with the country's electricity mainly being generated through oil-fired steam, combustion gas turbines, and combined cycle and diesel (Binder 2011), even the modernization of the railway system, which will be mainly powered through electricity, is expected to significantly contribute to Jamaica's de-carbonization. Therefore, the transport sector in Jamaica will remain a major source of carbon emissions in the long-term.

\subsubsection{Social, Economic and Environmental Challenges to an Island Economy}

As a small island state in the Caribbean, Jamaica is confronted by additional social, economic and environmental challenges typical to remote island economies (see Tisdell 2009). A major challenge is the interface between policies and 
an economy with limited competition. Due to scale economies, governments of small island economies tend to resort more often to regulation to control prices as business companies and industries seek higher revenues in a non-competitive market (Tisdell 2009). However, the political connections of company owners and managers as well as the low bargaining leverage of governments against multinational companies will more likely limit the effect of the 'political will' on regulating the market.

Small island states like Jamaica are highly vulnerable to imperfect market competition (see O'Sullivan 2003), particularly when trade commodities are involved. With imperfect competition, sellers are keen to influence the prices to earn more profits, particularly when limitations are unclear. The high prices of commodities are attributed not only to the limited number of sellers or traders, but also to de facto monopolistic competition, because sellers are selling highly differentiated products. Furthermore, Jamaica's supply chain of commodities requires additional intermediaries, which further increase the costs of trade, as large traders are unable to connect to all dispersed small markets from various areas in urban and rural Jamaica.

The high prices of commodities are also attributed to Jamaica's relatively high transportation costs, as the energy for transportation is provided almost solely by finite fossil fuels (Bedward \& Simpson 2016). The limited number of inter-island transport options (McCalla 2016), as well as low frequency of transport connections in Jamaica, are responsible for the demand-supply imbalance following a situation where trade growth has outpaced the availability of transport services, leading to distorted signals about the demand for commodities (see Russell 2017). The carbon lock-in of Jamaica's economy sustains high transportation costs, as moving away from a carbon-intensive is inhibited by a complex set of other factors such as institutional barriers and high transition costs.

Like most small island countries, Jamaica has consistent trade deficits of around 20 percent of their GDP (Bank of Jamaica 2017). As of 2016, Jamaica had a negative trade balance of 3.55 billion USD in net imports (OEC 2017). Because trade accounts for around 50 percent of the GDP of Jamaica, lower demand of its bauxite used for aluminum production abroad will lead to significant losses in income. In addition, Jamaica is highly dependent on the United States as their main trading partner ( 52 percent of total trade), which undermines the resilience of the Jamaican economy. Related to these trade deficits, the negative capital flow in Jamaica is not only a sign of negative expectations with regards to economic growth, it also puts pressure on the economy. The -44.90 million USD capital flows in the second quarter of 2017 ( -81.50 million USD in the first quarter of 2017) (Bank of Jamaica 2017) demonstrate the relative weakness of the Jamaican 
capital market and reflect the poor investment environment in the country, which further hamper economic development, as investors are reluctant to provide capital for operations and research \& development.

Jamaica's trade deficits and negative capital flow are directly linked to the country's dependence on foreign aid and loans as well as on remittances from their citizens working abroad. Jamaica is one of the most indebted countries. It spends twice as much on debt repayment (1.2 billion USD) as it does on education and health combined (600 million USD) (Dearden 2013). Although Jamaica has repaid a total of 19.8 billion USD for its 18.5 billion USD debt, it still owes 7.8 billion USD as a result of high interest payments. In addition, Jamaica's debt is inhibiting income growth in Jamaica, due to austerity measures imposed by international lenders. For example, in exchange for an IMF loan of 1 billion USD in 2013, four years of austerity are responsible for a 20 percent real-term cut in wages (Dearden 2013). Huge debt has been a constant burden for Jamaica for four decades, where the economy has effectively not grown since 1990. Natural disasters, such as Hurricane Sandy in 2012, have further increased indebtedness, as Jamaica seeks foreign aid and loans for its rebook.

To summarize, Jamaica seems to be trapped by carbon lock-ins and the resulting unfavorable economic conditions undermining the country's attractiveness to foreign investors. While the tourism sector remains vibrant, partly due to austerity measures, Jamaica is lagging in improving infrastructure in non-tourist areas, further inhibiting economic growth (Durrant 2016). Although its energy demand is almost solely covered by imported fossil fuels, the country's efforts to expand the use of renewables are effectively hindered by the tendency of fossil fuel energy systems to be cheaper, better understood, and perceived as easier to employ.

A major factor that reinforces Jamaica's carbon lock-in is the behavior of the society as a whole (see Binger 2011). Carbon lock-ins are deeply embedded in the consumption behavior of the majority of the Jamaican population. Jamaica is confronted with a high-consumption society, in which the consumption of commodities (e.g., household appliances and motor vehicles) is hardly driven by efficiency considerations. While the Jamaican government has already initiated discussions aiming at giving energy efficiency and renewable energy more important roles in the country's energy system (Wood 2016), it has been lagging, due to gaps in the kind of policy that aims to effectively raise awareness of the connections between lifestyle and energy use (Binger 2011). Moreover, because political attention tends to be given to renewables, the country fails to address the improvement of energy efficiency, because of the inherent belief that savings in energy costs will mainly come from the deployment of renewable energy options. 


\subsubsection{Institutional Barriers}

Functioning institutions are necessary for the successful deployment of sustainable energy, and ineffective institutions are a critical barrier to its growth (Knight 2016). While small island countries tend to have a high need of regulation leading to a higher share of public sector employees in total employment, Jamaica's public sector is relatively small, hinting at capacity deficits in providing services to citizens. As of July 2017, the public sector accounts for 59,400 employees, which is 4.88 percent of the total 1,216,200 employed labor force in Jamaica (SIJ 2017). For comparative purposes, Nordic countries Denmark, Norway and Sweden have higher public-sector employment levels, reaching nearly or over 30 percent of total employment between 2009 and 2013. The United Kingdom and Barbados have, respectively, 23.5 percent and 22.03 percent of its total labor force working in the public sector (see OECD 2011). The public sectors of Caribbean countries the Bahamas and the Dominican Republic employ 33.7 percent (2009) and 12.8 percent (2013) of the total labor force respectively.

Explanations as to the relatively small public sector in Jamaica are often linked to the country's constant exposure to rigid austerity measures through its high debt. As the public sector is unable to compete with the private sector in the labor market for hiring employees with the needed technical expertise, the technical competence of Jamaican public sector's employees is often questioned, inhibiting trust in state institutions. With the fast pace of technological advancement, regulatory bodies tend to struggle to catch up with regulatory provisions to ensure that other society priorities are not undermined. While the public sector is still perceived as a source of stable jobs, it is often the first affected by austerity measures imposed by creditors (e.g. hiring freeze).

In addition, some experts argue that a small public sector is partly responsible for the relatively low salary of private sector employees (see Malley \& Moutous 1996; Algan et al. 2002; Burdett 2012). Nobel laureate in economics, Christopher Pissarides (2000), argues that the public sector competes with the private sector in attracting the best workers through so-called 'crowding out.' A small public sector like that in Jamaica cannot compete with the private sector. In addition, a larger public sector that can offer higher wages will most likely provide workers in the private sector more leverage when bargaining around salaries and additional benefits. Therefore, the public sector also influences the level of income in the private sector.

Sustainable low carbon transformation needs a public sector that is significantly capable of dedicating resources, for example, to address complex energy 
issues that are intertwined with other policy goals. Although government officials need to horizontally and vertically coordinate with colleagues from other government agencies and ministries, they will more likely find it difficult to collaborate in the context of competition for limited public resources following impositions of austerity. For example, sustainable, low-carbon transformation requires the exchange of updated information necessary for sustainable energy planning. The entanglement of various aspects of energy sector governance will bear witness to the cross-cutting of competencies of a vast array of agencies and government structures, which may lead to a lack of clarity about final decisions in the energy sector or unnecessarily prolong or complicate permitting processes. Such a long and complicated permit process may further hinder the entry of renewable energy technologies. Due to their wide-ranging and often cross-sectoral responsibilities, many government officials lack the detailed knowledge of sustainable energy technologies, their economic and financial requirements, and alternative mechanisms for their effective support.

With this contextualization of the various stumbling blocks to sustainable, low-carbon transformation, it is important that carbon lock-ins be identified, conceptualized and addressed through an integrated approach to make policy-makers understand and concretize missed opportunities. The next section aims to provide an integrated understanding of the requisites of Jamaica's sustainable, low-carbon transformation. What changes are needed to be implemented to effectively address lock-ins and related caveats?

\subsection{The Agency and Audience of Sustainable, Low- Carbon Transformation in Jamaica}

\subsubsection{Jamaica's Response to the Paris Climate Agreement}

Like many developing countries, Jamaica connotes climate change with vulnerability. As a small island developing state, Jamaica is particularly vulnerable to the impacts of climate change. Jamaica's economic development is at risk, because its major economic sectors such as tourism, agriculture, forestry and water are climate-sensitive (UNFCCC 2015). As such, like in the Philippines, political discourse and narratives on climate change in Jamaica evolve mainly around adaptation and seldom around mitigation. Nevertheless, Jamaica has announced that it intends to play its part in reducing GHG emissions through 'no regrets' emission measures (UNFCCC 2015). Emission reduction is also mainly framed from the 
perspective of energy security, as Jamaica seeks to resolve risks and threats to its energy supply system.

Jamaica became the $143^{\text {rd }}$ country to ratify the Paris Climate Agreement on April 11, 2017 when the Minister without Portfolio of the Ministry of Economic Growth and Job Creation officially presented the instrument of ratification at the National Climate Change Conversation organized by the Ministry's Climate Change division (UNDP 2017). With Jamaica's ratification of the Paris Agreement, the INDCs have been adopted as NDCs, Jamaica will revise and update its NDCs by 2020 and will continue to update every 5 years thereafter.

The ratification was expected, because the agreement is aligned with Jamaica's existing domestic policies. Climate change has been 'mainstreamed' in Jamaica's policy-making, which will integrate mitigation and adaptation in present and future policies. Jamaica's National Development Plan, Vision 2030, which is the country's long-term, sustainable development program recognizes the need for a healthy, natural environment. Other key policies that support the ratification and implementation are the Second National Communication (2011), the Climate Change Policy Framework (2013) and the National Energy Policy 2009-2030 (2009). A major element of Jamaica's climate policy is, as mentioned, climate change adaptation. Jamaica has developed a Strategic Program for Climate Resilience (SPCR), as part of the Pilot Program for Climate Resilience (PPCR), to decrease Jamaica's vulnerability to the effects of climate change.

In terms of mitigation, Jamaica's intended nationally-determined contribution (INDC) will mitigate the equivalent of 1.1 million metric tons of carbon dioxide per year by 2030 or a reduction of 7.8 percent of emissions compared to the business-as-usual (BAU) scenario of growth without policy intervention, which uses 2005 as a base year (UNFCCC 2015). However, under this BAU scenario, GHG emissions from Jamaica would increase by 37 percent by 2030 , which implies a massive gap between expected emission increase and INDC under the BAU scenario. In addition, Jamaica will conditionally increase its aim to a reduction of GHG emissions of 10 percent below the BAU scenario, subject to the provision of international support. The Jamaican government aims to significantly reduce emissions growth and achieve its NDCs through a program of modernization of energy infrastructure and diversification of energy sources towards cleaner and renewable fuels (20 percent by 2030), pursuing opportunities for energy conservation and incentivizing efficiency. The Climate Change Division of the Ministry of Water, Land, Environment and Climate Change will coordinate the actions of various ministries, departments and agencies in implementing Jamaica's INDCs. 


\subsubsection{Entry Points to Climate Mitigation, Energy Security and Sustainable Development}

Entry points to climate mitigation, energy security and sustainable development in Jamaica can be identified through the contextualization of policy and market instruments.

\subsubsection{Embedding the Informal Economy into Sustainable, Low-Carbon Transformation}

The informal segment of the Jamaican economy is a significant issue when assessing sustainable, low-carbon transformation, because its size is estimated to be between 40 and 60 percent of the country's official GDP (Torero et al. 2006) (compared with 16.1 percent of GDP in OECD countries or 8.4 percent in the United States, see Schneider 2005). With the established connections between the informal economy and emission growth (see Abid 2015; Bento et al. 2017), sustainable, low-carbon transformation needs to include efforts not only to 'formalize' this segment of the economy, but also recognize the potential 'entrepreneurial spirit' of informal sectors (see Soto 1986) that could be conducive to sustainable, low-carbon transformation.

The informal economy a broad range of activities conducted in the informal sector can be condensed to identify several common characteristics that includes all employment that is not bound by contract or other legal regulations, smallscale operations, unregistered businesses, and all activities which generate revenue that is not reported to tax authorities (Graham 2016). While the informal economy in Jamaica is usually attributed to a loss of tax revenues, which is estimated to be around about 800 billion JMD in nominal terms per year, as well as to the evasion of environmental regulations and the vulnerability of workers due to a lack of government protection ( 70 percent of workers do not have legal contracts, see Torero et al. 2006), its impact on Jamaica's sustainable, low-carbon transformation remains a huge knowledge gap. If the informal economy is largely unaccounted for in sustainable, low-carbon modelling, policy approaches and scientific \& policy analysis, the effectiveness of policy instruments can be a major source of uncertainty (see Benson et al. 2014). Nevertheless, including the informal economy in sustainable, low-carbon policy-making will be needed to fairly address the reasons why there is an informal economy in the country in the first place.

For example, one possible reason for the existence of the informal economy is the lack of political will to address this, because formalization will most likely 
further burden the poor. The informal economy is often seen as a major source of employment for those who do not have access to human capital. In addition, the informal economy is composed of various activities that are often reactions to fluctuations in the formal economy and provide 'cushions' in times of economic crises, as unemployed people are able to secure income through the informal economy (Benson et al. 2014). In addition, because the informal economy is largely unaccounted for, it is difficult to come up with categories or types of informal economic entities, especially as these entities cover different sectors such as energy, agri-food, trade, mining, housing and waste management. While some of these are not major emitters, such as street vendors, or are even are helpful to the environment, such as informal waste-picking (see Benson et al. 2014), others such as artisan mining, informal housing, and car repair shops, are contributing significantly to environmental degradation through uncontrolled and unmonitored pollution (see Abid 2015, Blackman and Bannister 1998; Lahiri-Dutt 2004).

Various studies and reports have identified microenterprises in wholesale/ retail trade and agriculture as the main entities of Jamaica's informal economy by employing almost 60 percent of the workers in the informal economy, followed by manufacturing as a distant third (see Torero et al. 2006). These microenterprises contribute to the income generation of women in particular (57 percent of the total number of workers in the informal economy, see Torero et al. 2006) and supply various commodities particularly needed in the rural areas of the country. Nevertheless, while some of these entities are financially incapable of installing technologically advanced pollution control equipment, others refuse to install such pollution control, particularly when the government is most likely unable to monitor and control these entities (see Blackmann 2000).

Calculating the amount of emissions from the Jamaican informal economy can only depend on 'honest estimates.' Therefore, the potential benefits of engaging the informal economy for sustainable, low-carbon transformation will need to look beyond mitigation to innovation at the grassroots level. As possibly implied by the significant number of microenterprises in the informal economy of Jamaica run by tertiary graduates (around 33 percent), the informal sector in the country can be tapped as an important driver of sustainable, low-carbon transformation. However, engaging Jamaica's informal economy to commit to sustainable, low-carbon transformation will require the inclusion of non-state actors. The actors of the informal economy will most likely prefer the non-intervention of state actors, whose forms of formalization such as licenses, fees, and permits are linked to additional costs and limitations. 


\subsubsection{Sustainable Tourism-Efficient Hotel Buildings}

As tourism is a huge source of revenue and employment in Jamaica, mitigation efforts that will affect the tourism sector will require careful implementation. The direct contribution of travel and tourism to Jamaica's GDP was 1.4 billion USD or 9.3 percent of total GDP in 2016 and is forecast to rise by 4.6 percent in 2016 , and to rise by 5 percent per year from 2017 to 2027 to 13.4 percent of total GDP by 2027 (WTTC 2017). In addition, travel and tourism directly supported 97,000 jobs (8.4 percent of total employment), which is expected to rise by 4.1 percent in 2017 and by 4.4 percent per year to 155,000 jobs or 12.2 percent of total employment by 2027 (WTTC 2017). When jobs indirectly supported by the sector are included in the calculation, the total contribution of the travel and tourism sector in 2016 was 27.5 percent of total employment (318,500 jobs). It is furthermore expected that total employment will rise by 4.3 percent in 2017 and by 4.4 percent in 2027 to a total of 40 percent (WTTC 2017).

With the expected growth of the travel and tourism sector, without additional climate policies, the sector will be a major source of emissions. Nevertheless, the sector can benefit from mitigation policies by contextualizing (co-benefits and synergies) new investment and decision frameworks (including narratives). While government mitigation policies can, for example, focus on reducing electricity costs, particularly those needed for the cooling of hotels, through the gradual replacement of imported fossil fuels and the deployment of renewable energies for a long-term perspective, the sector can actively highlight investments in enhancing energy efficiency. Particularly with the expected warming in Jamaica, hotels burdened with the crippling effects of higher electricity costs can be supported through new policies on demand and supply. The tourism sector can be further motivated to address these challenges through policy and market instruments to promote efficient buildings that will significantly reduce energy consumption. Nevertheless, the tourism sector will need additional support to achieve energy efficiency while it addresses the effects of climate change such as sealevel rise, extreme weather events and erosion.

\subsection{A Simulation Game-The Jamaican Energy Policy Under Austerity Measures}

The energy policy game focuses on putting forward austerity measures which will create 250,000 jobs while reducing its debts to 117 percent of GDP, modernize the public sector by strengthening government capacity and effectiveness, 
enhance energy security and energy efficiency to reduce its dependence on oil, and generate additional income to stabilize government spending (25 percent of the 2016/2017 government budget) of $\mathbf{J} \$ \mathbf{1 4 7 . 5}$ billion. Emphasis is also placed on evaluating the risks and barriers of the chosen measures (risks, unhappiness and ecological damage).

\subsubsection{The Background of the Game}

The newly elected Prime Minister Andrew Holness of the Jamaican Labour Party (JLP) has promised to reverse the hard austerity measures dictated by the International Monetary Fund (IMF). In 2010, Jamaica needed the US $\$ 1.27$ billion IMF loan to support its plan to recover from mounting government debt, weak economic growth, and the effects of the global financial crisis. While the government was able to restore economic stability, these measures are often regarded as unsustainable, because the reduction of budget deficits was primarily attributed to the effect of low oil prices which allowed the government to reduce its spending on oil imports. The current low oil price gives the government a reprieve, but if Jamaica wants to have sustainable economic growth, it cannot speculate solely on global oil prices, especially because of the political crisis in Venezuela which might lead to the cancellation of the agreement providing Jamaica with cheap oil. It needs to take on the program to break the cycle of high debt (currently about 140\% of GDP) and low growth, trapping Jamaica in a cycle of debt service and borrowing for decades.

The new government cannot reverse the reforms stipulated by the IMF loan. The government understands that the obstacles to Jamaica's growth and job creation are numerous and severe. As identified by the IMF, the key problems for Jamaica are: crime, the cost and availability of credit, tax compliance costs, unreliable and expensive electricity, and a large informal economy. The IMF has also identified the need to address the large size of the public sector that has also stifled private sector dynamism and places too much emphasis on government as the engine of growth and employment.

\subsubsection{The Game-Goals and Instruction}

The new government has tasked an expert panel with making recommendations to improve the fiscal standing of Jamaica. The expert panel has produced a list 
of possible measures. The cabinet of the government conducts a meeting to evaluate the austerity measures suggested by the panel. Furthermore, the government has tasked this panel with recommending measures to meet the following goals while meeting the austerity goals set by the International Monetary Fund:

- Create more than 250,000 jobs while reducing its debt to $117 \%$ (debt to GDP ratio) in 2017.

- Modernize the public sector by strengthening government capacity and effectiveness

- Create an enabling environment for the private sector by fostering investments in high-potential sectors,

- Build social and climate resilience by strengthening social safety nets and by supporting the development of a comprehensive framework for disaster and climate risk management

- Enhance energy security and energy efficiency to reduce dependence on oil imports.

As members of the government cabinet, participants need to evaluate the measures presented and choose which measures are to be implemented to meet these political goals. This should be done while considering the social, economic, and environmental sustainability of these specific measures. Furthermore, participants should identify possible conflict cleavages, conflict parties, issues and other negative externalities and provide "compensatory measures" (including the costs of these measures).

The participants should follow the following steps:

The first step is to generate additional sources of income to allow muchneeded investment and to finance the increase of the income tax rate threshold (from $\mathrm{J} \$ 592,800$ to $\mathrm{J} \$ 1,000.272$ ). The assumed amount of needed additional income to stabilize government spending is 25 percent of the 2016/2017 government budget or $\mathbf{J} \$ \mathbf{1 4 7 . 5}$ billion.

The second step after generating additional sources of income is to choose and evaluate measures that would implement the goals mentioned above. The expert panel have identified additional sources of funding available to developing countries under the framework of various development funds such as the climate fund or the clean development mechanism. The participants need to check Jamaica's eligibility for this additional funding. 
The third step is to evaluate the risks and barriers of the chosen measures. For this game, each option shows the expected costs and expected revenues. Costs are shown as: Risk Points (RPs), Unhappiness Points (UPs) and Ecological Damage Points (EDPs)

Some measures are linked with risks (the probability that the measure will not work as well as externalities, trade-offs and co-benefits), public discontent or public resistance (leading to street protests and more social unrest), and ecological damage points (leading to environmental damages). Aside from the goal of generating or saving $\mathbf{J} \$ \mathbf{1 4 7 . 5}$ billion, no set of austerity measures is allowed to have more than 10 RPs, 10 UPs and 2 EDPs.

Participants may decide to alter a specific value. For example, in suggesting measure no. 4, a tax may be introduced with a 20 percent increase (instead of 10 percent as the expert committee suggested). This will lead to an additional 75 percent of the initial value to reflect the marginal benefits of values. In turn, the RPs and UPs will be doubled, and EDP tripled. Some measures cannot be altered or doubled (marked with *).

\subsubsection{Results and Interpretation}

The three groups have produced a set of decisions as summarized by the following three figures:

Group 1 (PHMEL) was able to come up with actual budget cuts totaling 127.043 billion JMD. Adjusting this number to consider the marginal benefits, the group achieved a budget cut of a total of $\mathbf{1 0 6 . 8 4}$ billion JMD. Marginal benefit adjustment refers to some measures that were doubled (or tripled) compared to the figures given by the expert panel. Group 1 decided to double the figures of the selected austerity measures (2a, 2b, 2c, 13, 14, 16, 17, and 20). Nevertheless, a doubling the provision on increasing income tax will not lead to a doubling of the savings, because of the expected marginal benefit of factor 0.75 . Both numbers are short of the required $\mathbf{1 4 7 . 5}$ billion JMD. In comparison, Group 2 (HVSP) achieved budget cuts of a total of $\mathbf{1 2 5 . 8 0 4}$ billion JMD. Interestingly, the group decided to bridge the remaining amount through additional foreign loans and grants. Group 3 (AGBPB) on the other hand achieved cuts of a total of $\mathbf{1 5 0 . 8 5 4}$ billion JMD, which surpasses the required 147.5 billion JMD goal. When asked how the group was able to negotiate savings with such relative ease, 
the group claimed they focused on the direct and indirect benefits of each austerity measure. When it became apparent that 'harsh' austerity measures would later yield to additional benefits, negotiations became less contested.

In terms of limitations to the Risk Points (RPs) (10), Unhappiness Points (UPs) (10) and Ecological Damage Points (EDPs) (2), group 1 met the limitations on UPs and EDPs with -9 and -27 points respectively. However, with 14 RPs, group 1 surpassed the allowed RPs. Group 2 managed to meet all the limitations on points. With $10 \mathrm{RPs}, 0.5$ UPs and -14 EDPs, it is expected that the budget cuts will not face fierce political and social resistance. Group 3 produced a set of austerity measures with the most favorable points. With $10 \mathrm{RPs},-2.5 \mathrm{UPs}$ and -24.5 EDPs, group 3 vindicated the pattern of the usefulness of linking environmental protection with other policy priorities. When environmental benefits of economic and political measures are 'concretized,' the linkages become clear and are easier to embed in their decisions. Furthermore, with the surprisingly 'good EDPs' of all groups, discussions were made whether a 'points trade' should be made possible following a similar principle of carbon trading, with RPs to be substituted by UPs and EDPs. This 'trade' can be further pursued in real life to facilitate decision-making.

Due to time constraints, groups 1 and 2 were not able to discuss the other aspects of the game, such as the identification of relevant stakeholders as well as the expected co-benefits and synergies, which could have provided them with additional resources to legitimize the austerity measures or to even bargain for further budget cuts. It was difficult for them to connect austerity measures with the creation of more than 250,000 jobs while reducing its debt to 117 percent (debt to GDP ratio). A possible explanation for this difficulty is that they did not completely understand the rationale behind the 'points.'

On the other hand, Group 3 was able to initiate the assessment of budget savings using the imposed conditions, because the group tried to understand why a specific austerity measure was too risky to implement. For example, when a measure was expected to lead to job cuts, this measure was combined with discussions about contingencies such as additional policy instruments for job creation. This linkage made contextualization possible. In addition, by identifying the ministries and other related government agencies, group 3 was able to have an overview of the required government capacity that is needed to ensure the effectiveness of the implementation of the austerity measures, while maximizing their co-benefits and minimizing the risks (Table 12.1). 
Table 12.1 Example: The Results of Group 1 (PHMEL) (own representation)

\begin{tabular}{|c|c|c|c|c|c|c|c|}
\hline \multirow[t]{3}{*}{ No } & Measure & \multicolumn{2}{|c|}{ Benefit(Jmd) Billion } & \multirow[t]{2}{*}{ RP } & \multirow[t]{2}{*}{ UP } & \multirow[t]{2}{*}{ EDP } & \multirow[t]{2}{*}{ Modified } \\
\hline & & Generate & Save & & & & \\
\hline & & 139,0425714 & $.20,2$ & 13 & .9 & .26 & \\
\hline & & 118,842 & & & & & \\
\hline \multirow{3}{*}{2} & a & 0,525 & & 0 & 0 & 0 & Doubled \\
\hline & $b$ & 0.7 & & -1 & -1 & 0 & Doubled \\
\hline & c & 0,75 & & -2 & -2 & 0 & Doubled \\
\hline 3 & 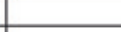 & 0.5 & & -1 & -1 & 0 & \\
\hline 4 & 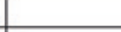 & 0.6 & & 0 & 0.5 & 0 & \\
\hline \multirow{3}{*}{5} & a & 0.3 & & 0.5 & 1 & 0 & \\
\hline & b & 0.55 & & 0.5 & 0.5 & 0 & \\
\hline & c & 0.8 & & 0 & -1 & 0 & \\
\hline 6 & $\mathrm{a}$ & 0.3 & & 0 & -1 & 0 & \\
\hline \multirow[t]{2}{*}{7} & $b$ & 1,628571429 & & 0.5 & 1 & 0 & \\
\hline & c & 4,375 & & 1 & -1 & 0 & \\
\hline 8 & a & 4. & & 0,5 & 1 & 0 & \\
\hline 9 & 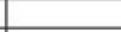 & 1,8 & & 1 & 1 & -1 & \\
\hline 10 & . & 3 & & 1 & 0 & -1 & \\
\hline 11 & c & & -0.2 & -2 & -2 & -2 & \\
\hline \multirow{3}{*}{12} & $b$ & 6.489 & & 1 & 0,5 & -2 & \\
\hline & $c$ & 3. & & 0.5 & 0,5 & -2 & \\
\hline & e & 12. & & 1,5 & 1 & -4 & \\
\hline 13 & & 3.5 & & 1 & 2 & -4 & Doubled \\
\hline 14 & & 7,05 & & 1 & 1 & -8 & Doubled \\
\hline 15 & & 3.6 & & 0 & 0,5 & 0 & \\
\hline 16 & & 9.275 & & 4 & -2 & 0 & Doubled \\
\hline 17 & & 7. & & 2 & 0 & -2 & Doubled \\
\hline 18 & & 5.3 & & 2 & -1 & 0 & \\
\hline 19 & & 4 & & 0,5 & 0,5 & 1 & \\
\hline 20 & & 3.5 & & 2 & -4 & 0 & Doubled \\
\hline 23 & & 3 & & 0 & 0.5 & 0 & \\
\hline 25 & & 5 & & 1 & 2 & 0 & \\
\hline 26 & & 8 & & 0.5 & 1 & 0 & \\
\hline 27 & & 4 & & 0.5 & 0 & 0 & \\
\hline 28 & & 10 & & 3 & - & & \\
\hline 29 & & 3 & & & 1 & & \\
\hline 30 & & 1 & & 1 & 0.5 & -2 & \\
\hline 31 & & 8 & & 0,5 & 1 & & \\
\hline \multirow{4}{*}{32} & $a$ & & -1 & -2 & -2 & 0 & \\
\hline & $b$ & & -2 & -1 & -2 & -1 & \\
\hline & c & & -4 & -2 & -2 & 0 & \\
\hline & d & & -3 & -1 & -2 & 2 & \\
\hline 33 & & & -10 & -2 & -3 & 0 & \\
\hline \multirow{2}{*}{34} & $a$ & 0.5 & & 1 & 1 & -1 & \\
\hline & c & 7 & & 0 & 1 & -1 & \\
\hline 36 & & 5 & 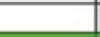 & -1 & -1 & 2 & \\
\hline Actual & & 127.0425714 & 20,2 & 14 & 9 & .27 & \\
\hline Target & & 36,375 & 111,125 & 10. & 10. & 2 & \\
\hline & & \multicolumn{2}{|c|}{106,8425714} & & & & \\
\hline
\end{tabular}




\subsubsection{Observations from the Behavioral and Negotiation Point of View}

The author of this book/game designer added and highlighted some game parameters that would test the negotiation behavior of the participants. As noticed by the participants (and written in the questionnaire), the need to negotiate with other stakeholders (other ministries) made decision-making very complex.

The following is a selection of observations made by the game master during the game:

\section{Group 1}

- Group 1, which consisted of all male participants, spent a significant amount of time (around $60 \%$ of time) discussing the procedures that were to be followed. However, after the group was able to find consensus about the procedures, the bargaining interactions became easier to conduct.

- There was a general impression that the participants were 'territorial,' because the discussions were often about the limitations of what they could accept as representative of a specific ministry. Because of this, it was difficult for a participant to assume the role of a facilitator in the negotiations. Often, a participant who was indifferent to a specific issue intuitively mediated between participants who were obviously unable to move forward because of differences.

- Interestingly, on various occasions, humor (use of jokes) was used to 'deflate' some tensions between parties.

- Group 1 used all possible technical tools to make the visualization of values easier, such as the projection of an excel table showing all the measures that they have already reached. This visualization gave the group additional motivation to work together as they become solution-oriented.

\section{Group 2}

- Group 2, which consisted of all female participants, focused on the fairness aspects of the provisions. The deliberations were often framed by concepts of fairness and equity. Interestingly, the participants apparently had a similar definition of fairness and equity, as one session of the module was dedicated to understanding the concept of fairness and justice. This gives the idea that it is important for participants of any negotiation to have a basic understanding of such concepts, as this will effectively facilitate negotiations. 
- Group 2 consisted of four participants who applied different negotiation styles (competitive, collaborative, cooperative, avoiding). One participant was highly competitive, two were rather collaborative and the remaining one was an avoider.

- The two collaborative participants were able to 'contain' the competitive participant by highlighting benchmarks and objective standards. Because of this, the deliberations became highly analytical.

\section{Group 3}

- Group 3 consisted of both male and female participants. There were no clear gender-based implications of this composition.

- Interestingly, one participant connected to the group through Skype. Nevertheless, as expected, the internet connection was difficult, and he was disconnected most of the time. During the times he was briefly connected, he tried to unilaterally dictate the course of the negotiation until the connection failed again. This can be explained by his motivation to compensate for his absence. Nevertheless, the connection difficulty significantly delayed the negotiations, because the discussion was constantly repeated for the sake of the missing participant. This experience implies the importance of 'institutional memory' and 'personal connections' during deliberations. A participant that is new to the group will need additional time to catch up with the obvious and latent information and the related signals needed to agree on decisions.

- All (except for the skype participant) were collaborative during the negotiations.

\subsection{The Ideal Type of Democratic Policy-Making Under Low Capacity and Low Autonomy-The Role of Austerity Measures and Carbon Lock-Ins in Jamaica}

Jamaica has developed into one of the most stable democracies in the Caribbean region. While some election periods, such as the 1980 general elections, which was marked by over 800 casualties, have witnessed sporadic violence, Jamaica has never experienced a successful coup attempt since its independence in 1962, and although elections were often delayed by the incumbent government, elections have been regularly conducted and the opposition party is regularly able to win elections. 


\subsubsection{The Material Value of Democracy in Jamaica}

As identified in chapter 8, the manner in which political actors are able to align their political interests with public opinion or how they can shape public opinion is an important subject of analysis of policy-making in democratic countries. Jamaica's "dumb" democracy is currently challenged by legitimacy deficits as implied by the downward trend of voter turnouts since 1944 (The Gleaner 2016). The perception of disconnect between politics and societal interests fuels political apathy, especially among the youth, which weakens civil society engagement. In turn, political apathy further reinforces legitimacy gaps. For example, approximately 28 percent of the votes from the eligible electorate was enough to give a two-thirds majority in the House of Representatives to the People's National Party (PNP) in the 2011 elections. This was slightly improved in the following elections. In 2016, the Jamaica Labour Party (JLP) won the General Elections held on 25 February 2016 with 50 percent of votes (or 32 out of 63 seats) with only 47.7 percent voter turnout, which was the lowest since 1983 , the year when the PNP boycotted the election.

Because many democratic countries tend to rely solely on elections as source of political mandate, input legitimacy is often taken as 'default,' evident and given. As such, some governments and state institutions do not see the need to build up their capacities to effectively engage and facilitate persuasive interactions. As long as their decisions are within the boundaries set by the constitution, no additional efforts are identified and implemented to build the capacities of other stakeholders to actually and effectively participate in persuasion and bargaining regimes. In Jamaica, while there is a stable democratic regime, state institutions are often overwhelmed by several lock-ins and structural impediments. For example, Jamaica's dependence on fossil fuels and bargaining interactions that are allowed to define how the country will achieve sustainable, low-carbon transformation is not creating enough new impulses for the necessary changes.

As the ideal type of the democratic policy model suggests, the transformation process is not only dependent on the interactions between the three streams, but also on the drivers and brakes. In Jamaica's case, carbon lock-ins have impeded stream alignments. In addition, local conditions, such as 'brain drain', have inhibited consensus-building, as important stakeholders have limited technical capacity to actually contribute to consensus-building.

Carbon lock-ins limit the perceived available and feasible sets of decisions (and policies) in many ways, which constrain efforts to promote sustainable, low-carbon transformation. State institutions are confronted by its low autonomy 
and low capacity in facilitating functional, institutional, and bargaining interactions among relevant stakeholders. The low autonomy of Jamaican institutions pertains to the multiple dependencies of these institutions on designing, implementing and monitoring policies. Jamaica's high dependence on foreign loans and remittances, as well as the related imposed austerity measures limit the ability of Jamaican policy-makers to make independent decisions without undermining its access to future loans. Low autonomy (translated to the tolerable window') is, for example, not being determined through streams alignment, but by foreign lenders and carbon lock-ins. Therefore, existing guard-rails tend to favor non-sustainable and high-carbon policies.

Jamaica's low capacity can be significantly attributed to its relatively small size (around 4 percent of the total labor force). This and the paradoxical public perception that the Jamaican public sector is 'too big,' implying legitimacy deficits, limiting its institutional capacity to address complex and intertwined issues in order to pursue sustainable, low-carbon transformation. Jamaica's low capacity is further reinforced by 'brain drain', as the country lacks policy entrepreneurs with both technical expertise and knowledge of the local context. Knowledge diplomacy is therefore a huge challenge as technical and academic studies relevant to Jamaica's sustainable, low-carbon transformation is not able to catch up with emerging necessities. As such, Jamaican policy-makers, for example, often resort to studies and reports published by international bodies with limited (local) contextual value.

In addition, the rather weak social movement or civil society working on sustainable development and environmental/climate protection in Jamaica pave way for certain (business) actors that represent the fossil fuel sector to over-proportionately influence policy entrepreneurship (also called lobbying). Nevertheless, there are several environmental NGOs such as the Nature Conservancy which helped to create the Blue and John Crow Mountain National Park for which it brokered a Debt for Nature Swap (see GRICCE 2017) that are actively engaged with international donors to support environmental and climate protection in Jamaica. However, there are significant missed opportunities that can be adequately addressed with a more empowered Jamaican civil society. The general civic discontent and political apathy of a significant part of the population are symptoms both of the low autonomy and low capacity of state institutions, which further induce limitations to any transformation process in Jamaica, as potential partners for transformation are effectively alienated and disenfranchised (see Campbell 2016). 


\subsection{Conclusion-Capacity-Building as Key to Jamaica's Sustainable, Low-Carbon Transformation}

\subsubsection{Lessons for Theory}

The ideal type analysis of Jamaica's policy model has led to some theoretical challenges. The simulation game highlighted the co-benefits of various austerity measures. The identification of these co-benefits and other synergies was made possible through the contextualization of each measure. As the positive and negative externalities of each measure were identified, it became evident that negative externalities, when properly addressed by compensatory measures, may create new values, for example for climate protection or job creation. A lesson for theory is that 'empathy' can be the key to any transformation process, as addressing multiple perspectives can actually expand the value of a specific measure. Nevertheless, expanding the value might require additional investment, which requires a long-term outlook.

\subsubsection{Lessons for Practice}

Jamaica lacks local scholars who have the methodological and scientific expertise to produce studies that meet high academic validity standards. Because epistemic communities play a huge role in understanding the complexities of climate change and of how climate protection, energy security, and sustainable development interplay, Jamaica's sustainable, low-carbon transformation will necessitate an unprecedented upgrade of its pool of experts. In addition, Jamaica's pool of technical experts should not only come from government agencies, but also from independent research institutes that are able to pursue both basic and applied research without depending on either the government or the business/industry sectors.

Moreover, the capacity-building of scientific communities in Jamaica will need to find a balance between propriety and access to public goods. Through various interviews of local experts and scientists, it became apparent that Jamaican universities tend not to share information and data with other scholars (both within the same organizations and between organizations) for propriety reasons. This outlook can be attributed to the dependence of research on private funding. 
There is a need to address the 'angst' of researchers and research institutes, because a sustainable, low-carbon transformation will require more inter- and intra-disciplinary collaboration to effectively address complex issues that supersede disciplinary boundaries. As one institute produces a set of data, other institutes may be in a better position to assess the meaning and implication of these data. Another policy-oriented institute may be better at transforming the data and its assessment into policy recommendations as other contextual factors are embedded into the analysis. The Jamaican government needs to ensure access to relevant knowledge to support the maturation process and the adaption of knowledge to Jamaican specificities.

In the same manner, Jamaica needs to upgrade the capacity of its civil society to participate in consensus-building processes. Linked to this is the need to effectively address the latent disconnect between policy-making and the societal mandate. This can be done, for example, by initiating ambitious consultations on structural reforms. Effective consultations are, however, contingent on social actors that are able to formulate and advocate for various societal priorities such as environmental protection, civil rights and liberties, equity, and social innovation. Jamaica needs to improve its social capital if it wants to achieve sustainable, low-carbon transformation.

Open Access This chapter is licensed under the terms of the Creative Commons Attribution 4.0 International License (http://creativecommons.org/licenses/by/4.0/), which permits use, sharing, adaptation, distribution and reproduction in any medium or format, as long as you give appropriate credit to the original author(s) and the source, provide a link to the Creative Commons license and indicate if changes were made.

The images or other third party material in this chapter are included in the chapter's Creative Commons license, unless indicated otherwise in a credit line to the material. If material is not included in the chapter's Creative Commons license and your intended use is not permitted by statutory regulation or exceeds the permitted use, you will need to obtain permission directly from the copyright holder.

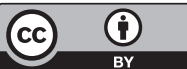

